\title{
The NAS-NRC Twin Registry of WWII Military Veteran Twins
}

\author{
William F. Page \\ Medical Follow-up Agency, Institute of Medicine, Washington, DC, USA
}

\begin{abstract}
The NAS-NRC Twin Registry is one of the oldest, national population based-twin registries in the United States. It consists of 15,924 white male twin pairs born in the years 1917-1927 (inclusive) both of whom served in the armed forces. The registry, which has been in operation more than 30 years, has collected data from a variety of sources. Recordsbased, computerized data have come largely from the Department of Veterans Affairs, and there have been three major epidemiologic questionnaires, undertaken roughly every 15 years. Classic twin studies on a variety of medical conditions were the early focus of the registry, which now has a strong focus on chronic disease epidemiology. Work on a DNA specimen bank has been proceeding slowly, but is now a top priority, due to the increasing force of mortality in this twin cohort.
\end{abstract}

The National Academy of Sciences-National Research Council (NAS-NRC) Twin Registry is one of the largest twin registries in the United States and is a national, rather than regional or state, registry. ${ }^{1}$ The Registry is a program of the Medical Follow-up Agency, a division of the Institute of Medicine, which is part of the National Academy of Sciences (NAS) complex. The NAS is a private corporation established by federal charter, which was created by an Act of Congress and signed in 1863 by President Abraham Lincoln. The NRC is the operating arm of the NAS, created in 1916, while the Institute of Medicine was chartered under the NAS in 1970 as a national institution committed to the advancement of health sciences and education and to the improvement of health care.

\section{Origins of the NAS-NRC Twin Registry}

The Medical Follow-Up Agency (MFUA) was created shortly after WWII in response to a request by the U.S. military to the National Academy of Sciences. Dr. Michael DeBakey, then a colonel in the U.S. Army's Office of the Surgeon General, played a pivotal role in MFUA's early development. In 1955, efforts began to identify twins who had served in the Armed Forces during World War II. Copies of birth certificates of white male twins born in the years 1917-1927 were matched against Department of Veterans Affairs (VA, then the Veterans Administration) files to determine veteran status. Some 54,000 pairs of birth certificates were obtained from 42 vital statistics offices, and eventually 15,924 of these pairs were identified by the VA as veterans. These 31,848 individual twins constitute the NAS-NRC Twin Registry (Jablon et al., 1967). Over the years, many research studies, ranging over a wide variety of medical topics, have been undertaken using the Registry.

\section{Advantages of the NAS-NRC Registry}

Two of the advantages the NAS-NRC Twin Registry enjoys are its population-based ascertainment and the veteran status of its members. In contrast to registries that are created using samples chosen entirely on clinical grounds, often from within institutions specialising in the treatment of a narrow class of disorders, or registries created using volunteers, the NAS-NRC Twin Registry essentially includes the population of WWII twins who were military veterans. Due to the cooperation of the states when the NAS-NRC Twin Registry was assembled, it is estimated that $93 \%$ of multiple births of males during 1917-1927 in the United States were identified and subsequently screened for veteran status. The virtual completeness of the population-based ascertainment in the Registry is a valuable asset.

The fact that the members of the NAS-NRC Twin Registry are veterans has some important practical advantages and is not, per se, a material factor in their health, except that veterans are, as a whole, more healthy than the general population because they had to pass a screening physical to enter military service. Specifically, Registry members' military records contain valuable basic demographic and health data. The eligibility of veterans for benefits such as disability compensation and hospitalization provides an opportunity to collect such data from VA records relatively efficiently. The eligibility of a decedent war veteran's family for VA death benefits similarly permits the ascertainment of vital status using VA records, a process that has been shown to be quite complete (Page et al., 1995). In addition, three major epidemiologic surveys have been sent to members of the Registry and their responses added to the database of information (see below). The restriction of Registry members to white males obviously limits opportunities for some studies, but also provides a certain degree of sample homogeneity.

\section{$\overline{\text { Data Collected }}$ Zygosity}

Zygosity is determined from information obtained by questionnaire, from military records (physical characteristics

The opinions and assertions contained herein are those of the author and are not to be construed as reflecting the views or positions of the National Academy of Sciences, the Institute of Medicine, or the National Research Council.

Address for correspondence: William Page, Medical Follow-up Agency (FO3072), Institute of Medicine, 500 5th St NW, RM776, Washington, DC 20001 USA. Email: wpage@nas.edu 
such as height, weight, eye and hair color), fingerprint records, and (for a subsample) blood group testing (Hrubec \& Neel, 1978; Jablon et al., 1967). The items used in the questionnaire were essentially translations of those used in the Swedish and Danish twin registries and established the correct zygosity (compared with blood group) $95 \%$ of the time (Jablon et al., 1967).

\section{Records Data}

Data abstracted from hard-copy military records include the data on physical characteristics (height, weight, eye color, hair color) as well as additional items from the induction physical (blood pressure, ABO blood group, and Rh factor), and administrative data (date of birth, military service number, branch of service, date of entry into active duty, date of separation from service, and rank). Some additional data, such as medical defects at induction physical (e.g., number of missing teeth) were captured on abstract forms but were not computerized. While in many cases the original military records were burned in an accidental fire in St. Louis, the abstracted data are still available on microfiche.

Records of the Department of Veterans Affairs (then the Veterans Administration, VA) provided a wealth of data. There are computerized VA records on military disability, hospitalization, and fairly recently, outpatient care (Boyko et al., 2000). The VA's file of veteran beneficiaries provides information on vital status, as well as a link to a hard-copy death certificate, in most cases. A study of the completeness of reporting of veteran twin deaths found that mortality ascertainment among WWII twins was 96\% complete (Page et al., 1995).

\section{Questionnaire Data}

Three major epidemiologic surveys have gathered data via mail questionnaire. Data from these surveys is shown in Table 1. The surveys were undertaken in 1967, 1983, and 2000 , with the number of twin pair respondents numbering 4700, 3600, and 2060, respectively. There is a core of items common to them all, providing valuable longitudinal data. Data on alcohol and tobacco consumption, for example, have proven particularly valuable (Carmelli et al., 1992; Carmelli \& Page, 1996). In addition, over the years there have been a number of special purpose data collection efforts. For example, data on earnings, obtained for a sample of registry participants, formed the basis of a monograph on socioeconomic success and the effects of genetics, family environment, and schooling (Behrman et al., 1980). Current special purpose data collections include four successive "waves" of telephone interviews, with emphasis on Alzheimer's disease (Breitner et al., 1995; Gallo \& Breitner, 1995) and Parkinson's disease (Tanner et al., 1999; Tanner et al., 2002), among other things.

\section{DNA Specimens}

Because the Registry has been in operation primarily before the genomic era, the number of DNA samples is small. For example, certain studies (e.g., Alzheimer's disease) are collecting DNA on a relatively small group of affected twins and their co-twins. In addition, a recently funded study of longevity is expected to provide DNA
Table 1

Information on Three Major Epidemiologic Questionnaires in the NASNRC Twin Registry

\begin{tabular}{|c|c|c|c|}
\hline Information & $\begin{array}{l}\text { First } \\
\text { estionnaire } \\
\text { (02) }\end{array}$ & $\begin{array}{c}\text { Second } \\
\text { Questionnaire } \\
\text { (07) }\end{array}$ & $\begin{array}{c}\text { Third } \\
\text { e Questionnaire } \\
\text { (08) }\end{array}$ \\
\hline Date & 1967 & 1983 & 2000 \\
\hline Number of pairs responding & 4700 & 3600 & 2060 \\
\hline \multicolumn{4}{|l|}{ Selected core items } \\
\hline Height and weight & yes & yes & yes \\
\hline Angina questionnaire & yes & yes & no \\
\hline Food preferences & yes & yes & no \\
\hline Smoking habits & yes & yes & yes \\
\hline Drinking habits & yes & yes & yes \\
\hline Marital status & yes & yes & yes \\
\hline Number of children & yes & yes & no \\
\hline Medical conditions & yes & yes & yes \\
\hline \multicolumn{4}{|l|}{ Selected special items } \\
\hline Residential history & yes & no & no \\
\hline $\begin{array}{l}\text { Raised with your twin? } \\
\text { Mother's/father's }\end{array}$ & yes & no & no \\
\hline occupation & yes & no & no \\
\hline Employment history & no & yes & no \\
\hline Retirement plans & yes & yes & no \\
\hline Job satisfaction & no & yes & no \\
\hline Social contacts & no & yes & yes \\
\hline Number of blocks walked? & no & no & yes \\
\hline Activity limitations & no & yes & yes \\
\hline Mother/father living? & no & no & yes \\
\hline Medications & no & no & yes \\
\hline Depression scale & no & no & yes \\
\hline
\end{tabular}

samples for roughly 800 healthy twin pairs. All samples are, in theory, part of consolidated database and potentially available to outside investigators, with appropriate approvals (see section, Access to the Registry).

\section{Example Studies}

Perhaps the best way to gain an appreciation for the types of studies that can be done using the Registry is to examine some examples.

\section{Genetic Influences on Smoking}

The recently completed study of genetic influences on smoking is a classic example of the use of the NAS-NRC Twin Registry. Data on smoking were taken from a questionnaire survey done in 1967-1969, when the twins were 40-50 years old, and from a resurvey conducted in 1983-1985, when they were 56 to 66 . Although the rate of smoking is quite high among these twins - $80 \%$ had smoked at some time in their lives - the proportion of current smokers declined from $60 \%$ to $39 \%$ from the first to the second survey. The availability of these longitudinal smoking data was crucial to the study.

As noted above, the classic twin analysis compares concordance rates for $\mathrm{MZ}$ twins with those of $\mathrm{DZ}$ twins, and if the former are larger, this is considered evidence of a genetic influence. Using the 1967-1969 data for both MZ and DZ twins, observed concordance rates were compared across four categories of smoking: (1) never smoked, (2) former smoker, (3) current cigarette smoker, and (4) 
current pipe or cigar smoker. In all four cases, $M Z$ twins had statistically higher concordance rates than DZ twins, suggesting genetic influence on different aspects of the smoking behavior. Comparing changes in smoking from 1967-1969 to 1983-1985, it was found that MZ twins were 1.24 times more concordant for quitting smoking than were DZ twins, evidence for a genetic influence on the ability to quit smoking (Carmelli et al., 1992). A subsequent study looked at the effects of smoking on 24-year mortality (Carmelli \& Page, 1996).

\section{Suicide in Twins}

Because suicide appears to cluster in families, suggesting a possible genetic influence, a twin study was undertaken. Data on 11 twin pairs from other sources were combined with data from 165 twin pairs from the NAS-NRC Registry for this classic analysis of heredity. The mortality data for the NAS-NRC twin pairs had been collected using VA records, which have been shown to be over $90 \%$ complete. Among the combined group of $\mathrm{MZ}$ twin pairs, the concordance rate for suicide was $11.3 \%$, whereas among the $\mathrm{DZ}$ pairs it was only $1.8 \%$, suggesting that genetic factors play a role in suicide (Roy et al., 1991).

\section{Alzheimer's Disease in Twins}

Investigators at Duke University Medical Center have taken a somewhat novel approach to studying the genetic and non-genetic influences on Alzheimer's disease (AD) in the members of the Registry. Beginning in 1990 and about every four years thereafter, they have identified Registry members with suspected cognitive impairment using a twostage telephone screening protocol. Individuals with possible dementia based on information collected during the screening interviews were then assessed in-person at their residence by a research nurse and psychometrician. Co-twins of affected twins also were evaluated either with in-person assessments or structured telephone interviews. Differential diagnoses of dementia were assigned after review of all information from the assessments by a team of neurologists, geriatric psychiatrists and neuropsychologists.

Based on the first wave of data collection (1990-1993), probandwise concordance rates for Alzheimer's disease were $24 \%$ for monozygotic pairs and 9\% for dizygotic pairs (Meyer \& Breitner, 1998). These rates were notably lower than those reported by other twin studies of Alzheimer's disease, most likely reflecting the low prevalence of $\mathrm{AD}$ in the Registry at the relatively young mean age of 68 years. As predicted, the concordance rates for Alzheimer's disease have increased somewhat as the Registry members get older and reach the more typical age of onset (75-90 years) for AD. To date, 164 twin pairs with one or more members with $\mathrm{AD}$ have been identified. This number will increase as the fourth wave of data collection, now underway, is completed.

\section{Longevity}

A subset of pairs in the NAS-NRC twin registry is being recruited where one or both pairs have reached their $70 \mathrm{~s}$ with a trait defined as "wellness". These twins, as of the Q8 questionnaire, reported not ever having had a heart attack, stroke, coronary bypass surgery or angioplasty, diabetes mellitus, or prostate cancer. Blood samples are being collected for DNA extraction and immortalized cell lines established for pairs in which one of the parents of the twins lived to be over age 90. Initial recruitment has focused on DZ pairs, and a preliminary analysis of genome wide scanning data of the first 81 pairs of DZ twins concordant for wellness has identified six different chromosome regions having microsatellite markers with lod scores greater than 1.0.

Over the years, the Registry has shown itself to be quite flexible in accommodating studies over a wide range of topics: atopic dermatitis, schizophrenia, manic-depressive illness, headache, multiple sclerosis, cancer mortality, alcoholic cirrhosis, Alzheimer's disease, Parkinson's disease, and stroke, among others.

\section{The NHLBI Subsample}

In the 1960 s, a sample of 514 twin pairs from the Registry was selected for examination under the sponsorship of the National Heart, Lung, and Blood Institute of the National Institutes of Health. The twin pairs were selected for their proximity (within 200 miles) to one of five study centers (Framingham, Mass.; Indianapolis, Ind.; Davis, San Francisco, or Los Angeles, Calif.), and four examinations of this group have been made: in 1969-1973, in 1980-1981, in 1986-1987, and in 1995-1997. These longitudinal examination data have been the basis of many important clinical studies.

A number of studies of heritability have been undertaken in the NHLBI group, including studies of hypertension, ischemic heart disease, cognitive performance, and obesity, among others. For example, it was shown that there are two independent genetic contributions to body mass index (a frequent measure of obesity): one that affects obesity in young adulthood and one that operates in middle age. This finding is evidence that although some genes related to obesity are set at birth, they may remain "silent" for decades and only be "turned on" later in life. The availability of longitudinal data from the NHLBI sample thus provides an significant opportunity to study the effect of genetic factors over time.

\section{Current Era Twins Registry}

The Current Era Twins Registry (CETR) is a panel of 440 twin pairs, both members of whom served in the Army in 1986 or later, with an additional 577 pairs in which only one twin has agreed to participate in the registry. In contrast to the NAS-NRC Twin Registry, CETR contains both men and women and is more ethnically diverse. There are plans to expand CETR by including other military branches and by identifying twins as they enter basic training.

\section{Operating Principles}

The NAS-NRC Twin Registry operates under a set of principles designed to maintain and protect the Registry as a resource for research. Requests for access to the Registry are carefully considered to protect the twins' privacy against unwarranted intrusion; to avoid unauthorized disclosure of confidential information and unnecessary harm caused by experimental manipulation; to assure that the scientific 
value of each proposed study is weighed against the financial and social costs to be incurred; to prevent too frequent contact of the twins by investigators or conflicting demands by different investigators; and to coordinate the efforts of the investigators. For these reasons, every application for access to the Registry is reviewed by the Twins Committee (see below).

\section{Access to the Registry}

Access to the NAS-NRC Twin Registry is available to qualified researchers whose use of the Registry is deemed appropriate by the Medical Follow-up Agency's Twins Committee. The Committee evaluates proposals according to the principles outlined above and may request supplemental information or make recommendations about technical aspects of the proposed study. Access to the Registry is granted only upon approval by the Committee.

Investigators are required to limit their contact with Registry subjects to that detailed in their application and to agree not to undertake any additional contact except upon submission and approval of a supplemental application. Initial solicitation of the twins is made under the Registry's auspices, and only if the twins consent to participate in a study may they be contacted subsequently by the investigators. The National Academy of Sciences' Human Subjects Committee reviews and approves all twin studies that involve subject contact. All information obtained from the twins becomes a part of the Registry and may be made available to future investigators.

The Registry receives no funding for its core program which obtains current information (address, vital status and cause of death, hospitalisations, etc.) from various outside sources and uses it to update the Registry. Investigators are therefore expected to contribute toward these expenses. Current registry maintenance fees are $\$ 35,000$ per year for studies collecting data (plus additional project-specific costs, if they are applicable) or a one-time fee of $\$ 10,000$ for provision of data file (with identifiers removed) for secondary data analyses.

Brief letters of interest outlining a proposed area of research in the Registry are welcomed and may be sent to the Director, NAS-NRC Twin Registry, Medical Followup Agency, 500 Fifth Street, N.W., Washington, DC 20001. If there are no current studies in the area of interest, a follow-up proposal will be solicited for review by the Twins Committee.

\section{Current Membership of the Twins Committee}

Irving I. Gottesman, Ph.D., University of Minnesota, Chair; Caleb E. Finch, Ph.D., University of Southern California; Joe C. Christian, M.D., M.P.H., Indiana University School of Medicine; Jack Goldberg, PhD, University of Washington; John C. S. Breitner, MD, MPH, University of Washington; Eric Boerwinkle, Ph.D., University of Texas Health Science Center at Houston; Andrew Heath, D. Phil.; Washington University School of Medicine; Joanne M. Meyer, Ph.D., Millennium Pharmaceuticals, Inc.; Nicholas J. Schork, Ph.D., Case Western Reserve University.

\section{Footnote}

1 The website of the NAS-NRC Twin Registry of WWII Military Veteran twins can be accessed at www.iom.edu/twins

\section{References}

Behrman, J. R., Hrubec, Z., Taubman, P., \& Wales T. J. (1980). Socioeconomic success: A study of the effects of genetic endowment, family environment, and schooling. New York: North-Holland Publishing Co.

Boyko, E. J., Koepsell, T. D., Gaziano, J. M., Horner, R. D., \& Feussner, J. R. (2000). US Department of Veterans Affairs medical care system as a resource to epidemiologists. American Journal of Epidemiology 151, 307-314.

Breitner, J. C., Welsh, K. A., Gau, B. A., McDonald, W. M., Steffens, D. C., Saunders, A. M., et al. (1995). Alzheimer's disease in the National Academy of Sciences - National Research Council Registry of aging twin veterans. III. Detection of cases, longitudinal results, and observations of twin concordance. Archives of Neurology, 52, 763-771.

Carmelli, D., Swan, G. E., Robinette, D., \& Fabsitz, R. (1992). Genetic influences on smoking - A study of male twins. New England Journal of Medicine, 327, 829-833.

Carmelli, D., \& Page, W. F. (1996). Twenty-four year mortality in World War II US male veteran twins discordant for cigarette smoking. International Journal of Epidemiology, 25, 554-559.

Gallo, J. J., \& Breitner, J. C. (1995). Alzheimer's disease in the National Academy of Sciences - National Research Council Registry of aging twin veterans. IV. Performance characteristics of a two-stage telephone screening procedure for Alzheimer's dementia. Psychological Medicine, 25, 1211-1219.

Hrubec, Z., \& Neel, J. V. (1978). The National Academy of Sciences-National Research Council Twin Registry: Ten years of operation. In W. E. Nance (Ed.) Twin Research: Proceedings of the Second International Congress on Twin Studies, Washington, DC (1977): Part B. Biology and Epidemiology. New York: Alan R. Liss.

Jablon, S., Neel, J. V., Gershowitz, H., \& Atkinson, G. F. (1967). The NAS-NRC twin panel: Methods of construction of the panel, zygosity diagnosis, and proposed use. American Journal of Human Genetics 19, 133-161.

Meyer, J. M., \& Breitner, J. C. S. (1998). Multiple threshold model for the onset of Alzheimer's disease in the NAS-NRC twin panel. American Journal of Medical Genetics (Neuropsychiatric Genetics), 81, 92-97.

Page, W. F., Braun, M .M., \& Caporaso, N. E. (1995). Ascertainment of mortality in the U.S. veteran population: World War II veteran twins. Military Medicine, 160, 351-355.

Roy, A., Segal, N. L., Centerwall, B. S., \& Robinette, C. D. (1991). Suicide in twins. Archives of General Psychiatry, $48,29-32$.

Tanner, C. M., Ottman, R., Goldman, S. M., Ellenberg, J., Chan, P., Mayeux, R., \& Langston, J. W. (1999). Parkinson disease in twins: An etiologic study. Journal of the American Medical Association, 281, 341-346.

Tanner, C. M., Goldman, S. M., Aston, D. A., Ottman, R., Ellenberg, J., Mayeux, R., et al. (2002). Smoking and Parkinson's disease in twins. Neurology, 58, 581-588. 